\title{
Entering the era of limits and scarcity: the radical implications for social theory
}

\author{
Ted Trainer ${ }^{1}$ \\ Independent scholar, Sydney, Australia
}

\begin{abstract}
The article argues that contemporary social theory has not recognized the significance of Limits to Growth. A global overshoot in resource consumption suggests we are at a dramatic turning point in human history, the end of the era of constant 'wealth' expansion and the beginning of an era of severe limits and scarcity. This has profound implications for critical social thought, and for addressing current social problems. Recognizing limits will influence the form that a sustainable and just society must take, and transitions to it. Radical and large scale 'de-growth' involves localized, cooperative, frugal, self-sufficient and selfgoverning lifestyles, settlements and systems. Key elements in the required 'Simpler Way' are discussed as workable and attractive. More importantly, the article argues that these transitions are non-negotiable; no alternative can resolve the predicament of limits. There are important implications for transition theory and practice. Social theory will pursue new directions in this context, with greater convergence around support for an Anarchist perspective on social goals and means.
\end{abstract}

Keywords: Limits to growth, social theory, transition, alternatives, The Simpler Way

\section{Résumé}

L'article soutient que la théorie sociale contemporaine n'a pas reconnu l'importance de Limits to Growth. Un dépassement mondial de la consommation de ressources suggère que nous sommes à un tournant dramatique de l'histoire de l'humanité, à la fin de l'ère d'expansion constante de la «richesse» et au début d'une ère de limites sévères et de pénurie. Cela a de profondes implications pour la pensée sociale critique et pour résoudre les problèmes sociaux actuels. Reconnaître les limites influera sur la forme qu'une société durable et juste doit prendre et sur les transitions qui en découlent. La «décroissance» radicale et à grande échelle implique des modes de vie localisés, coopératifs, frugaux, autosuffisants et autonomes. Les éléments clés de la «Simpler Way» (Voie plus simple) requise sont discutés comme étant exploitables et attrayants. Plus important encore, l'article affirme que ces transitions ne sont pas négociables; aucune alternative ne peut résoudre le problème des limites. Il y a des implications importantes pour la théorie et la pratique de la transition. La théorie sociale poursuivra de nouvelles directions dans ce contexte, avec une plus grande convergence autour du soutien d'une perspective anarchiste sur des objectifs et des moyens sociaux.

Mots-clés: Limites à la croissance, théorie sociale, transition, alternatives, «The Simpler Way»

\section{Abstract Spanish (coming)}

\footnotetext{
${ }^{1}$ Dr. Ted (F.E.) Trainer, Pigface Point, Kensington, NSW, Australia and retired, University of New South Wales, Australia. Email: tedtrainertsw "at" gmail.com. Thankyou to two reviewers for detailed comments. Their practical suggestions could not all be incorporated here, but are addressed in other 'The Simpler Way' publications cited in the references. Financial assistance; none.
} 


\section{Introduction}

The extensive popular and academic literatures on global problems such as climate change, resource depletion, ecological destruction and armed conflict, generally portray them as mistakes amenable to technical solutions, which leave the basic structure and values of consumer-capitalist society intact. Thus it is important for the following discussion to begin by putting the case that the 'limits to growth' predicament is of such a nature and magnitude that it cannot be solved without more radical change than even the traditional Marxist left has imagined. The following case is based on the claim that a sustainable society must be defined in terms of massive de-growth to mostly small scale and highly self-sufficient local economies, a very low GDP per capita which is zero-growth, frugal lifestyles, and a cultural transition away from preoccupation with wealth, materialism, individualism and competition. These principles contradict the main assumptions and goals taken-for-granted in most theorizing about the nature of existing societies, the nature of the good society, progress, emancipation, revolution and utopia. These are likely to be seen as extreme claims, so it is necessary to begin by sketching the case supporting them.

First, however, it is important to set out the argument. The first claim is that there is a coercive logic whereby if the initial 'limits' thesis is accepted, then conclusions regarding a sustainable, just and fulfilling society follow more or less irrefutably. Similarly, if the requirement for new social forms is accepted, it is difficult to dispute the conclusions regarding transition to such a society. Secondly, the degree to which each of these two claims will be regarded as satisfactory options by society, i.e., as achievable and desirable, will depend on how persuasive the exposition of the alternative social form and the path to it appear to be. Therefore much the following discussion involves advocacy of a sort, i.e., it seeks to persuade the reader that the alternative social forms and processes required by the limits to growth would be workable and attractive.

\section{The predicament}

The beginning point is the global "limits to growth predicament" (for a more detailed analysis, see TSW 2017). Rates of resource consumption and ecological impact are now far beyond levels that that are sustainable, or that technical advance could make sustainable, or that could be spread to all people. Present rich world per capita resource consumption levels are ten to fifteen times the average for the poorest half of the world's people. The scarcity of virtually all resources is increasing. Yet if all 9+ billion people likely to be living on earth by 2050 were to rise to the per capita level the rich world would then be at, given $3 \%$ p.a. economic growth, world resource demand would be in the range of twenty times its present level (UN 2015).

The determination to provide these levels of production and consumption is the basic cause of the major global problems. Because resources flow mostly to rich world consumers, most of the world's people are deprived of a just share. Those flows generate intense struggles to secure resources and markets, thus 
feeding into much of the armed conflict taking place and promising more intense resource wars in future (LeBillon and Duffy 2018). The alarming ecological damage occurring is primarily due to the fact that too many resources are being taken from nature, especially habitats, and too many wastes are being dumped back into ecosystems.

That these effects are occurring is widely understood, but what is not generally recognized is the magnitude of the overshoot, and it is this which determines that solutions must be radical in the extreme. An effective way of showing the magnitude is to refer briefly to the most commonly cited "Ecological Footprint" index. To provide the average Australian with food, settlement area, water and energy it takes about 7-8 ha of productive land (World Wildlife Fund 2014). If by 2050 the expected 9+ billion people were to have risen to the present 'living standard' in Australia or cognate rich world countries, and the planet's amount of productive land remains the same as it is today, then the amount available per capita would be 0.8 ha. In other words Australians today are using ten times the amount per capita that would be possible for all to use (note that a more inclusive index would lead to a much larger Footprint figure, and that by some estimates more than half the presently existing productive land will have been lost by 2050 ; Vidal 2010).

Many other measures confirm the grossly unsustainable nature of the present resource and ecological situation. For instance the top ten iron ore consuming countries have an average per capita rate of consumption that is around 80 times the average for all other countries (Weidmann et al. 2015). The WWF estimates that in the last few decades the mass of higher animals on the planet has been reduced by $40 \%$ (Carrington 2014), while that of big animals in the sea has declined by $90 \%$. We have entered the sixth era of massive biodiversity loss, with the rate now reported by Kolbert (2014) to be around 115 times the pre-industrial rate.

Above all there is now general acceptance (including by the IPCC) of the 'budgetary' approach to greenhouse gas accounting put forward by Meinshausen et al. (2009), whereby if there is to be a $75 \%$ chance of keeping temperature rise under 2 degrees by 2050 then no more than 1 billion tonnes of $\mathrm{CO}_{2} \mathrm{e}$ can be emitted after 2000. At the present emission rate that budget will have been completely used up by around 2033.

However this has only been an indication of the present grossly unsustainable situation. There is also the universal fundamental commitment to ceaseless growth in production, consumption, trade, investment, 'living standards', wealth and GDP. The impossible implications may easily be demonstrated. If 9 billion people were to rise to the GDP per capita Australians would have in 2050 given 3\% p.a. economic growth, then total world economic output would be approaching 30 times the present amount.

Why analyze in terms of the possibility of 9+ billion rising to anticipated rich world living standards? Firstly it is not morally acceptable to assume a difference in levels. Secondly that is the goal to which almost all nations are committed, so whether we like it or not we will have to deal with the feasibility and implications.

Rejection of the 'limits' case is usually based on the belief that technical advance will deal with the associated problems, that is, enable continued increase in production and consumption while bringing environmental impacts down to sustainable levels. It is not difficult to show the extreme implausibility of this claim (for a detailed critique see TSW 2016a). The core assumption is that resource use can be 'decoupled' from growth in economic output or GDP, i.e., that technical advances bring resource and environmental impacts down to sustainable levels while enabling continued GDP growth. But the above figures show the enormity of the reductions that would be required. Impact rates per unit of GDP would have to be cut to the region of $2 \%$ of present rates by 2050 . More importantly, all of the many studies of 'decoupling' find that in no field is growth being accompanied by a reduction in resource inputs (Weidmann et al. 2015; TSW 2016b).

To summarize, the overwhelmingly important conclusion to be drawn from the 'limits to growth' case is that the overshoot - the degree of unsustainability - is so great that a sustainable society cannot be defined other than in terms of de-growth to levels of per capita resource use, production, consumption and 
GDP that are a small fraction of present rich world or global levels (assuming these do not increase over time). The above figures indicate that the fraction is likely to be in the region of one-tenth of present Australian per capita levels.

Relatively little attention from the political far right to the far left has been given to the implications of this situation for social theory. Recognition of the significance of the limits to growth case sets a new agenda for social theory. It has numerous and far reaching implications. For instance it rules out reformist solutions; root and branch system changes in many economic, political and cultural areas are required. I also argue below that limits to growth analysis shows the inadequacy of basic Marxist theory regarding the required transition goals and means.

\section{The required alternative - the Simpler Way}

If present rich world per capita resource consumption rates must be cut dramatically, possibly by $90 \%$, there is a strong case that this cannot be done unless there is a transition to some kind of Simpler Way (for the detail see TSW 2018). For the rich world, this involves:

1. A profound cultural shift, to simpler lifestyles, involving far less production and consumption per capita, less concern with luxury, affluence, possessions and wealth, and instead a focus on non-material sources of life satisfaction. In addition the predominant outlook would have to be cooperative not competitive, much more collectivist and less individualistic. The enormity of such a cultural transition can hardly be exaggerated. It contradicts some core Enlightenment ideas and values.

2. Mostly small, highly self-sufficient local economies, largely independent of national or global economies, devoting local resources to meeting local needs, with little intra-state let alone international trade. This means transition from globalized to localized systems.

3. A new form of governance, primarily involving people in small communities taking cooperative and participatory control over their own local development, via voluntary committees, working bees and town meetings.

4. A new economy, one that is a small fraction of the size of the present economy, is not driven by profit or market forces, does not grow, and ensures that needs, rights, justice, welfare and ecological sustainability determine the purposes to which limited resources are devoted.

The main concern of the Simpler Way project has been to show that a society of this kind would be viable and could be easily built, in terms of technical ease, although the political and cultural changes would be difficult. It would provide a higher quality of life than most people experience in rich-world societies today. The detailed vision laid out in this and other publications is not offered as a precise prescription but as an illustration of possibilities intended to indicate feasibility (e.g., Alexander and Gleeson 2019; Simplicity Institute 2018; TSW 2018). As explained further below, the account generally corresponds to the nature of many existing eco-villages and to goals found within the Transition Towns movement (Aiken 2012; Henfrey and Ford 2017).

Following is a brief elaboration on some of the elements indicated by the above statement of principles.

Production of most basic goods by many small firms and farms (some cooperatives, some privately owned) within and close to settlements -- much use of intermediate and low technologies especially craft and hand-tool production, mainly for their quality of life benefits -- extensive development of commons providing many free goods especially 'edible landscapes' -- building using earth, enabling all people to have very low-cost modest housing -- voluntary working bees developing and maintaining community facilities -- conversion of existing towns and suburbs into highly self-sufficient communities -- many voluntary 
committees, e.g., for agriculture, care of aged, care of youth, entertainment and leisure, cultural activities - few paid officials -- large cashless, free goods and gifting sectors -- little need for transport, enabling bicycle access to work and conversion of most suburban roads to commons -- the need to work for a monetary income only one or two days a week, at a relaxed pace -- thus enabling much involvement in arts and crafts and community activities -- town-owned banks -- local currencies that do not involve interest -relatively little dependence on corporations, professionals, bureaucrats and high-tech ways - no unemployment; communities organize to use all productive labour and to ensure everyone has a livelihood (Trainer 1995).

The document Remaking settlements (TSW: 2016c) derives detailed tentative estimates supporting the claim that these procedures could cut the energy, dollar and footprint costs typical of a Sydney suburb by more than $90 \%$, while improving all dimensions of the quality of life. Reductions of this magnitude are also achieved by the Dancing Rabbit Eco-village in Missouri, USA (Lockyer 2017).

The crucial point here is that only in small, and highly integrated communities can per capita resource and ecological costs be dramatically reduced. For instance in a consumer society egg supply involves complex international networks for agribusiness and industrial feed and fertilizer production, production of steel for factories, tractors, shipping, warehousing, battery farming, logistics, advertising, trucks, super marketing, IT, finance, consultants, packaging, waste removal, and expensive technical skills. However eggs produced in backyards, community co-ops and local small farms eliminate almost all of these costs while adding benefits such as enabling 'waste' kitchen scraps to become chicken feed, and 'waste' chicken manures to go directly to soils, thus eliminating dependence on a fertilizer industry. The proximity and smallness of scale make possible much recycling and reuse, without need for transport etc., and enable arrangements and problem solving via spontaneous communication among neighbors, as well as creating community, leisure resources and resilience. A study of inputs to local egg production finds that dollar and energy costs are typically around $2 \%$ of eggs supplied by the commercial/industrial path (Trainer, Malik and Lenzen 2019).

Communities will function satisfactorily in these ways only if there are strong dispositions to cooperate, help others, take social responsibility, support community events, contribute to working bees and be concerned about the public good. The experience of living in the conditions described above tends to automatically elicit and reinforce these dispositions. All realize that their welfare derives not from individual income or property but from the solidarity and 'spiritual' wealth of their community. Compared with consumer-capitalist society, cooperation and collective values are encouraged and individualistic accumulation is not.

The economic focus therefore tends to shift from getting to giving; people know that when they give generously they are likely to receive abundantly. Whereas consumer society typically involves competitive and often less than zero-sum interactions, in The Simpler Way goodness generates further goodness and reinforces a climate of concern to see the other thrive. To give, care and contribute brings out in others appreciation and a desire to reciprocate. Thus the spiritual benefits of The Simpler Way become evident; it enables liberation from the major burdens of consumer society (where depression is one of the main illness now) and opens the way to a high quality of life for all despite, or more accurately because of, very low material 'living standards' (see TSW 2012, 2015a).

In a Simpler Way economy there would still be an important, though much reduced role for some more distant and centralized institutions, such as teaching hospitals, universities, steel works, large and complex factories, railway systems and wind farms. However there would be little or no need for many industries, such as advertising. The elimination of most of the present vast quantity of unnecessary productive effort would enable considerable increases in resources available to flow into arts, education and socially desirable research and development.

Although this vision involves decimation of per capita consumption rates it does not imply hardship or deprivation. It involves shifting to lifestyles and systems, which enable all to enjoy non-material sources of purpose and satisfaction. 
Over the past thirty years a concern to move in this general direction has emerged and is gathering momentum, most evident in the Permaculture, Voluntary Simplicity, Eco-village and Transition Towns literatures (for illustrative examples see TSW 2013 and 2015a). Lockyer's study of Dancing Rabbit Ecovillage in this journal (2017) reports $90+\%$ reductions in several resource use measures along with high quality of life indices (See also TSW 2010 and Grinde et al. 2018).

\section{The revolution is bigger than most have imagined}

The foregoing sketch of the limits predicament shows that solving current global problems is a far greater problem than most critical social theorists have recognized. Many, especially mainstream Marxists, have assumed that what is required is a change in ownership and control but then the same old goals of raising living standards and the GDP can be pursued via the same old means involving centralized, industrialized, globalized systems, technical advance and representative democracy (Albert 2003; Lowy 2015; Phillips 2014; Scharzer 2012). However what is needed is a multi-dimensional transition away from several of the most basic elements that have driven Western culture for more than two hundred years. The economic and political changes are daunting enough, but the most difficult elements are to do with ideas, values and culture. For example the universally taken for granted idea of progress that has been dominant since the Enlightenment has to be rethought to accommodate the notions of limits, irremediable scarcity, stability and frugality.

\section{The good society cannot be an affluent-industrial society}

The limits to growth analysis shows that capitalism is not the fundamental problem confronting the planet. When the limits are understood, it follows that a sustainable and acceptable world order cannot be achieved while a capitalist economy remains. But if it was eliminated and 'socialism' was implemented everywhere while the commitment to affluent living standards and to ceaselessly increasing the volume of production and consumption remained, then the range of sustainability problems currently on the agenda would more or less remain unaltered. The limits predicament means that a satisfactory, post-capitalist society cannot be an affluent, economically globalized, heavily industrialized, centralized or consumer society.

From The Simpler Way perspective, one of Marx's major mistakes was in thinking that a good society is not possible before the productive forces reach high levels of development. But many 'primitive' societies and presently functioning alternative communities show that only very low material living standards or levels of industrialization are necessary for a high quality of life. Also, many peasanthomesteaders and members of eco-villages live well, using little more than hand tools and natural materials such as earth, wood and leather, and being secure within cooperative social arrangements. Most of the more elaborate items they need can be produced in local factories, most using intermediate technologies.

The good life and the good society depend primarily on values and expectations, on having purpose and worthwhile work, on the richness of community and culture, and on the collective capacity to organize sensible systems. There is now considerable evidence that they do not depend much on material goods, income, monetary wealth, modern technology or the GDP (Alexander 2015; Eckersley 2004; Speth 2001). From The Simpler Way perspective, most of the poorest Third World countries also have greater GDP per capita and levels of technical sophistication than are necessary for a good society (although obviously they would need substantial restructuring and wealth distribution).

Thus a basic taken for granted premise under much critical social thinking is invalidated. This is the 'unidimensional assumption', i.e., that progress can only be conceived in terms of position and movement up the one 'modernizing' path from underdeveloped or primitive to modern and beyond, the essential parameters being levels of material wealth, capital invested and technical sophistication. But is it conceivable that the conditions necessary for a high quality of life can be achieved without high material 'living standards' or elaborate technology. In addition, there is a strong case that in general terms, affluence 
and technical complexity interfere with the achievement of those conditions (TSW 2015b, The case for simplicity).

Several contributors to "eco-socialism" (broadly defined) have made valuable contributions to the discussion of possible structures for post-capitalist society, including Kovel (2007), Albert on "Parecon" (2003), Lowy on eco-socialism (2015), Fotopoulos on "Inclusive Democracy" (1997), Foster (2008), Sarkar (1993) and Bookchin on "Social Ecology" (1980). However, while offering solutions, none of these theorists recognize the significance of scarcity and simplicity or grasp the crucial, game-changing fact that the good society cannot be an affluent society. None attempts to work out the implications for the form a society has to take to be satisfactory with very low resource use and material living standards. The need for intense frugality and localism, and a very different culture, are hardly recognized or discussed. Nor is imagining and debating the forms and functions of a workable alternative frugal, cooperative and localized society. Major concerns of The Simpler Way project are to show that the core elements in the required society are not optional and are beyond dispute. It proposes a possible structure and plausible ways of functioning. Above all, the concern is to show that quality of life could be much higher than in consumercapitalist society, and to show how easily this vision could be realized, if that was the widely accepted goal.

\section{Localism must replace globalization}

The present globalized economic system cannot function without a very high throughput of resources and energy, for mass production, transport of inputs and products, and for information technology. However as explained, the basic model for the coming era of scarcity must be the small scale, highly self-sufficient local economy, drawing mostly on local resources and local labor to meet local needs, with little trade within the nation, let alone within the world economy. There would need to be some remnant centralized, national and international agencies and functions but these could not be on a large scale.

When simpler ways are adopted, the scope for local provision is substantial. The study Remaking settlements (TSW 2016c) estimates that radical reorganization in a typical Western city could enable its outer suburbs to produce almost all food needed, along with a high proportion of many other basic goods and services, indicting the possibility of a $90 \%$ reduction from present Australian per capita energy and dollar costs.

These small scale, complex, integrated and self-governing local systems cannot be run from the political or economic center. Communities would have to be largely self-governing via participatory processes. State governments cannot impose or create such communities. They can only be created and run by the citizens who live in them, as they alone understand the conditions, history, geography, local social dynamics and needs. They will have to do the thinking, planning, decision-making, and implementation via committees, town meetings and working bees. These communities will not function satisfactorily unless people realize that their situation and fate are in their own hands, feel empowered and eager to run their town well, want to identify and solve their own problems, and are proud of the communities they have built.

We cannot assume that thriving communities of this kind will emerge automatically, easily, or at all. Given the probable situation ahead involving serious resource and ecological constraints, if a viable and satisfactory society is achieved, it will have to take the general form described. It hardly needs to be said that a strong case could be made out that this goal will not be achieved.

\section{The market must have no more than a minor role, if any}

In addition to enabling the pursuit of growth, market forces have a strong tendency to allocate most resources, opportunities to produce, and wealth to richer people. This why one-third of the world's grain is fed to animals mostly in rich countries, while almost one billion people are malnourished or worse. In a market system scarce goods go mostly to those who can pay more for them. Need is irrelevant. More importantly, when market forces determine development then investment flows into the most profitable 
ventures and not into development of the industries that can meet the urgent needs of the poorest billions, directly and most effectively. It is most profitable to devote grain to feedlot production of meat for richer people than to allocate it to poor people (see The case against the market, TSW 2014, and Third world development, TSW 2010).

In a context of severe scarcity, a satisfactory economy focuses on identifying and meeting local needs and gearing available resources directly to meeting them, mainly via collective, cooperative and participatory processes. This would require action independent of, and typically contrary to, market forces, with control in the hands of town assemblies and regional federations. A few functions would require more centralized arrangements but these could also be under participatory local control (Trainer 2012).

Although experience would determine the most workable arrangements, it is likely that all large enterprises such as steel works and railways would best be publicly owned, but from a Simpler Way perspective it is not necessary or desirable to 'socialize' all means of production or for the state to control or run everything. Local economies might be made up of small privately owned businesses and cooperatives, some operating within a remnant market system but all functioning according to strict limits and guidelines. The goal would be to preserve the scope for people in small businesses and co-operatives to have a secure asset base and to enjoy the freedom to organize their productive contributions in ways they prefer and enjoy. Collectivist attitudes and values would be essential but collective ownership of all productive property is not necessary; what matters is that productive property is used for socially desirable purposes. Social pressure would do most of the work, e.g., community refusal to buy from a baker if he or she tried to run others out of business. In existing ecovillages little such coercion is needed, but (some) sanctions would be necessary.

Capitalism took away from people their productive property and capacity to provide for themselves via customary and local economic processes, for instance through enclosures of common land in the early years. Marx did not seek to restore that capacity, that is, the ability of individuals and communities to have high levels of self-sufficiency, but The Simpler Way does.

\section{The supremacy of cultural factors}

The most easily criticized aspect of the Simpler Way vision is that it cannot work unless people cease to be interested in consuming and wealth accumulation and become far more responsible and conscientious citizens than they are now. This might seem to be an unrealistic requirement but it is nonnegotiable. The concern in most, if not all previous reformist and utopian visions has been to design systems that will work well enough despite the fallibility of humans. Hence the checks and balances and divisions of powers built into constitutions, and voluminous legal codes, and the readiness to impose authoritarian rule. But if we are to avoid being driven to chaotic and irretrievable breakdown in the coming era of limits and scarcity we will have no option but to develop self-managed local systems and these cannot function satisfactorily unless there is a high level of conscientiousness and responsibility among citizens.

However this might not be such a difficult goal because, as noted above, the situation will not only require these virtues but will also reward them through the experience of giving and receiving, cohesion and community, and the many intrinsic benefits of contributing to community. These spiritual conditions, the underlying world-views, values and dispositions, are the most crucial ingredients.

Thus in this revolution culture trumps economics, and politics. Kropotkin and Tolstoy realized this. They saw the ultimate revolutionary goal as largely autonomous citizen-run communities, and these cannot function, and cannot come into existence, unless the required vision and values have become predominant (Kropotkin 1898). Marx must be stood on his head; the necessary superstructures depend on the right ideas and values. 


\section{The transition process}

Nowhere are the radical and coercive implications of the limits more profound than with respect to the transition process. Again, the argument is that if the severity of the limits and the general nature of the alternative outlined above are accepted then it is difficult to dispute the main implications regarding the transition process that are sketched below.

\section{It will be a slow revolution}

A revolution that merely replaces one set of economic or political structures with another, or one set of owners and managers with another, might take place quickly. However, if there is to be a change to some kind of Simpler Way it cannot be rapid, because it has to involve fundamental change in ideas, values, dispositions, habits and established traditions. The transition process must, therefore be understood in terms of the slow development of a new vision and commitment, and in terms of a tapering down, phasing out and moving across, while groping towards alternatives (it is of course possible that there will not be sufficient time for this).

\section{An unavoidable, painful long march through capitalism?}

Central in Marx's theory of history is the belief that a system's adaptation in the face of contradictions, challenges and resistance produces social forms and institutions that both increasingly undermine it and are essential elements in the system that will eventually replace it (Marx 1887). He argued that to attempt to replace it before the institutions, ideas and ways the new system requires have developed is a mistake that will tempt a resort to force to drive change through. Use of force shows that conditions are not yet ripe, hence Marx's (sympathetic) critique of the Jacobins and the Paris Communards (1871).

This idea has been crucially significant in the modern history of revolution, especially the Russian revolution, leading various theoreticians to argue against action on the grounds that capitalism has not sufficiently matured to enable transition to socialism.

However late in his life Marx came to entertain the possibility of a quicker and more direct route to post-capitalist society, a route which did not involve first getting rid of capitalism. He toyed with the possibility that Russia, far from being even a bourgeoisie society, might go directly to socialism on the existing model of the Mir, the traditional peasant collective village (see Bideleux 1985; Bookchin 1977; Buber 1958; Kitching 1989 and Shanin 1983). It can be argued that the adherence of Kautsky and the Russian Marxists to the need to wait for the "laws of history" to produce capitalism in Russia and thus prepare the way for socialism, prevented this option from being taken. The Simpler Way perspective aligns with the notion of a 'direct path' that builds on developments in civil society, and that can begin to be taken well before capitalism self-destructs.

This issue again highlights Marx's neglect of the cultural factor. His discussion of the need for class consciousness seems only to involve the recognition by workers that the social system does not function in their interests. It certainly was not seen as involving the development of those individual psychological capacities without which an autonomous self-governing eco-village could not function, and nor did it involve any desire to live frugally.

Avineri (1968) makes this point clear in his discussion of Marx's ideas on the immediately postcapitalist period. Marx expected this to involve only a "crude communism" in which unsatisfactory attitudes and ideas regarding property, work, income, competition and acquisitiveness would remain. Workers would still be in the habit of working for a capitalist boss (in the form of the newly captured state), workers would still receive wages, would still accept division of labor, would still suffer alienation, and, most importantly here, would still be focused on the acquisition of property and material wealth. He thought that only in in a later stage would these dispositions be overcome, via a transformation of mentality/culture.

From the perspective of The Simper Way this is the wrong order of events. The shift of consciousness away from consumerism towards collective, local, frugal self-sufficiency will have to gather 
momentum long before capitalism is swept aside, or capitalism will not be replaced by a satisfactory society. A socialist revolution today, like all previous socialist campaigns, would surely attempt to provide industrialized affluence for all. Thus Simpler Way transition thinking focuses on attempting to build on those existing initiatives that can help to nudge consciousness and culture in the alternative direction, rather than on waiting for or working for the maturation and downfall of capitalism or the taking of state power. This aligns with the anarchism of Kropotkin and Tolstoy who prioritized the development of the appropriate vision, not the development of a vanguard party or the taking of state power (Marshall 1992: 372.) The latter are important problems and tasks but they will not become central until Stage 2 of this revolution (... and will then be relatively minor issues, if Stage 1 goes well; see below).

Marshall notes how force and power are of minimal relevance in the thinking of various classical anarchists such as Tolstoy, Gandhi and Kropotkin. Kropotkin urged revolutionaries simply to get on with the task of developing within their communities the awareness that would enable and motivate selfgovernment. If people would not rise to the opportunity to take control of their own affairs, this means there would be much consciousness-raising work still to be done (Marshall 1992: 372, 417, 615).

\section{Take state power?}

It follows that the essential traditional socialist strategy needs to be rethought. To Marxists it is crucial to seize and use state power but from the perspective of The Simpler Way it is a mistake to see this as a focal revolutionary strategy. It is not just ill-advised, it is a logical mistake. It will take place, eventually, but largely as a consequence of the revolution, not a cause or prerequisite.

Firstly, as explained, state power cannot make the new basic components of post-affluence society work. It does not matter how much control lies in the hands of the state or its benign bureaucrats or its secret police, this would be of no value in getting people to contribute willingly, conscientiously and happily to the new neighborhood and town socio-economic systems, or to work out how to run their unique local economy well. A distant state could not know what are the best ways for each little locality with its own idiosyncratic set of values, conditions, history, personalities and problems, and it could not make people want to find and practice those ways. Most importantly, communities can only become capable of running their own affairs satisfactorily if they learn how to do this through a long process of trying to do it.

But ...(the socialist is likely to protest), "... being in control of the state will enable the new ways to be introduced and facilitated. Control of the state will make it possible to work on that shift in mass consciousness." Consider the faulty logic here. There are only two ways that the control of the state for Simpler Way purposes could be acquired. The first is via some kind of coup whereby power is seized by a vanguard party, which has the intention of implementing The Simpler Way, and then converting uncomprehending masses to it. This is not very plausible. The second path would be via the election to government of a party that had a Simpler Way platform. But that could not happen unless the cultural revolution for a Simpler Way had previously been won. A Simpler Way party could not be elected to control of the state until after it had persuaded the majority of people to its ideas and proposals. Thus that revolution would be essentially constituted by the development of widespread acceptance of the Simpler Way vision.

\section{The role of the working class}

The left has a fundamental faith in the importance and the role of the working class. Unfortunately the traditional class interests of workers in capitalist society do not align well with The Simpler Way. They are about better work conditions, bigger pay checks enabling greater consumption, more jobs and production, more trade, a greater role for the state in running things, redistribution of wealth and provision of better 'welfare' by the state. The working class is strongly in favour of economic growth; higher 'living standards', better pensions and more state expenditure on health education, and especially more jobs, are seen to depend directly on how rapidly business turnover and GDP can be increased. Unions, socialist organizations and working class people in general are inclined to be hostile to any suggestion that there is a problem of affluence, industrialization or over-development, or a need to 'reduce living standards', which 
is understandable given that most people struggle financially. The left has insisted that the scarcities and deprivation will be resolved once expropriation by the capitalist class ends and the contradictions that capitalism imposes are eliminated. It is especially unsympathetic to any suggestion that the solution has to involve reduced per capita levels of consumption and a shift to simpler lifestyles. This is immediately seen as condemning those who are poor and struggling to even lower living standards.

At a deeper level there are problems to do with the situation and the psychology of the worker. Bookchin $(1973: 183,1977)$ points out that the industrial worker is intensely disciplined by the factory mode of production to acceptance of authoritarian conditions, the puritan work ethic, doing what one is told and not seeking autonomy or imagining a post-capitalist world. His or her experience does not include cooperating with others to take charge of his or her own situation, or to 'own' or feel responsibility regarding social problems. Illich (1973) emphasized the conditioned lack of autonomy and responsibility, and the readiness to leave things to corporations, governments and experts.

In addition the worker is a specialist, without the multi-skilled 'jack of all trades' orientation that the peasant, small businessperson or homesteader must have. The latter must be autonomous and responsible, monitoring, planning, fixing, adjusting, anticipating problems, improving, thinking about the whole system all the time. Workers can knock off at five pm and do not need to think about or assume responsibility for how well their factory or their neighborhood is going. The conditions they experience in an industrialized society tend to produce more interest in a good wage enabling a good car, shopping at a good supermarket, and watching a good large screen TV.

Marxists in particular seem not to have noticed that their present goals do not question the fundamental transition underlying the historical emergence of capitalism: when people lost their capacity to provide for themselves from their small plots and commons and collective arrangements and were forced to work for wages. The worker now needs a job and monetary wages to acquire necessities and the typical Marxist revolutionary vision does not challenge this. There is little or no interest in self-sufficiency, or the skills that enable it, such as gardening and craft. Industrialisation, electrification, centralization, globalization, infrastructures and freeing the forces of production from capitalist relations of production will provide the goods for workers to buy. There is no interest in enabling small communities to maximise their collective productive capacity and security outside the market. That is 'subsistence' and Marx in much of his work regarded it as a mode of production to be eliminated (however his later interest in the traditional village as a possible source of change might have been a departure from mainstream Marxism). The contrast with The Simpler Way could not be more stark, since it focuses on reversing the original separation of people from their means of production and the prevention of communities from controlling their own affairs.

Perhaps most significant is Bookchin's claim that the worker is not inclined to utopianism, to thinking in terms of a new and better society $(1973,1980)$. As he also points out, to Marx the industrial worker's revolutionary role is to revolt against one set of authoritarian rulers, and then submit to the next set. Like Avineri, he also notes that Marx did not think this issue of world view or 'personality' was important; it could be attended to long after the revolution as the vanguard gradually developed communist consciousness in the masses. However from The Simpler Way perspective the revolution cannot take place unless the required post-revolutionary consciousness has first become widespread at the grass roots level.

This revolution is not just or primarily about liberating the worker from capitalist conditions, it is about liberating all people from the ideology of consumer society, and all people, not just the working class, must be the drivers through their participation in the development of the emerging new local communities. The old left is being confronted here with the ultimate heresy, the possible irrelevance of class in this revolution. The era of scarcity is determining that the required revolution will not be brought about by a working class movement. Yet there is of course a mortal conflict of class interests at stake -- after all it is about whether or not capitalism and the capitalist class survive.

The corollary of the Marxist enshrinement of the worker is that after rule by the capitalist class ceases, workers will run things. But the new self-governing local communities will be dependent on the 
involvement of all to determine the technically and socially right decisions for the town, to make them work, and to maintain cohesion and enthusiasm.

\section{Hence a major tactical principle now would seem to be, do not confront capitalism}

It is understandable that when faced by an oppressive system it might seem necessary to turn towards it and fight it strenuously. There are situations in which this would clearly seem to be the appropriate response, and most if not all previous liberatory movements and revolutions have probably been of this kind. However I argue that the historically unique situation that global limits are bringing means that a nonconfrontational strategy is needed, one that involves turning away and 'ignoring capitalism to death.'

Consumer-capitalist society cannot survive if people do not continue to purchase, consume and throw away at an accelerating rate. The Simpler Way strategy (in the present early Stage 1 of the revolution) is to gradually build the alternative practices and systems which will enable more and more people to move out of the mainstream, to shun consumer society, and to secure more of their material and social needs from the alternative systems and sources emerging within their neighborhoods and towns. People will come across to The Simpler Way because as the ecological and financial crises intensify and seriously disrupt supply to their supermarkets they will increasingly come to realize that this is their best, indeed their only, option.

The radical left is strongly inclined to dismiss this approach as naïe, on the grounds that the rich and powerful do not willingly relinquish their dominant position. Yet this turning away strategy is now widespread, for instance among the large-scale Andean peasant movements, most notably the Zapatistas and the Via Campesino (Appfel-Marglin 1998: 39. See also Benholdt-Thompson and Mies 1999; Korten 1999: 262; Mies and Shiva 1993; Quinn 1999: 95, 137; Relocalise 2009; Rude 1998: 53). It is also growing in the richest countries, evident in the Transition Towns, Eco-village and alternative economy movements.

The standard Marxist retort here is that you cannot avoid having to fight the oppressive class because even if you manage to become a significant threat, it will crush you. But in the coming and unprecedented era of intense scarcity, it is not obvious that it will it be able to do this. Mason (2003), Korowicz (2012), Morgan (2013), Kunstler (2005) and Duncan (2013) are among those who discuss the multi-dimensional global breakdown likely to be brought on before long by limits and scarcity, probably an irretrievable plunge into deep and irremediable depression with the possibility of a die-off of billions. This will impact heavily on the power of ruling classes to maintain 'order', especially when the availability of liquid fuels is likely to be the major problem they face, when terminal collapse of the global financial system appears to be inevitable (debt levels are now far higher than before the GFC), and when their challenge is not striking workers that the army can be set on, but a multitude of community gardeners and co-operatives spreading throughout towns and suburbs.

This is not to say that the coming crises will see a Simpler Way emerge inevitably or peacefully. The probability that it will emerge at all would seem to be very low.

\section{The immediate practical implications?}

These theoretical considerations set the question, what should activists do here and now? The Simpler Way answer is more or less summed up in the anarchist notion of 'prefiguring', i.e., focusing on the building of post-revolutionary ways here and now within the existing consumer-capitalist society (Bookchin 1980: 263; Pepper 1996: 36, 305; Rai 1995: 99).

The point of prefiguring can easily be misunderstood. It is not primarily to increase the number of post-revolutionary ways that exist, and the assumption is not that just adding post-revolutionary arrangements one by one will end up with these having replaced consumer-capitalist ways. The main purpose is educational/ideological. By becoming involved in the many emerging local initiatives activists are likely to be in the most effective position to acquaint participants with the kind of global perspective 
argued above, and with the need to eventually go on from the present local preoccupations to the more distant and radical goals, the Stage 2 problems of growth, the market and the state.

The focal concern in this Stage 1 is slowly building an "Economy B" under the old economy, whereby local productive capacities are increasingly geared to meeting local needs via procedures which focus on collectivism, giving, quality of life, social cohesion, justice, concern for the public good, and sustainability. The key sub-goals here are to get to the point where citizens take control of their town and are no longer prepared to leave things to distant politicians and bureaucrats, and where they recognize that systems and lifestyles cannot be materially affluent.

\section{Stage 2 of the revolution}

Even the development of a very frugal local economy cannot get very far without relatively few but crucial inputs from the national economy, such as light steel, irrigation poly-pipe, cement, and chicken pen wire. This will generate pressure on states and national economies to move towards revolutionary macroscopic change. The towns will increasingly demand that the priorities of the center shift to focusing on providing the towns and regions with those relatively few inputs their survival depends on. They will insist that states organize redistribution of necessary industries so that all towns and regions can earn (small) incomes by exporting a few items into the national economy, to enable importation of those few items they need to get from it. Especially coercive will be the call for governments to facilitate the movement of workers from moribund industries to the new paradigm.

In time, this pressure is likely to shift from submitting requests to the state to making demands on it, and then to taking increasing control of it. There will be increasing insistence that frivolous industries must be phased out so that scarce resources can be devoted to meeting fundamental town and regional needs. Meanwhile towns will be driven by necessity to bypass the center and take initiatives such as setting up their own farms, energy supplies and factories, thus transferring various functions out of the control of the centre. There will be increasing recognition that the local is the only level where the right decisions for self-sufficient communities can be made. In time, these shifts will lead to the transfer of functions and power from state-level agencies to the local level, leaving the center with relatively few tasks, and mainly with the role of facilitating local activities.

This radical restructuring could conceivably be a smooth and peaceful process, driven by a general recognition that scarcity is making local self-governing communities the only viable option. If this happens then in effect, Stage 1 will be recognized as having constituted the revolution, essentially a cultural phenomenon, and the macroscopic structural changes in Stage 2 will be seen as a consequence of the revolution.

\section{Thus a case for Anarchist theory and practice}

It will be evident that the alternative social organization sketched above is a fairly common Anarchist vision (although there are also varieties that are not being advocated). The argument is that settlements enabling a high quality of life for all, despite very low resource use rates, must involve all members in thoroughly participatory deliberations regarding the design, development and running of their local productive, political and social systems. Their ethos must be non-hierarchical, cooperative and collectivist, seeking to avoid all forms of domination and to prioritize the public good. They must draw on the voluntary good will and energy of conscientious citizens who are ready to contribute generously and to identify and deal with problems informally and spontaneously, and to focus on seeking mutually beneficial arrangements with little if any need for industrial infrastructures and transport networks, bureaucracy, paid officials or politicians. Regional and wider issues will be tackled by the characteristic Anarchist mechanisms of federations and (powerless) delegates bringing recommendations back down to town meetings. The principle of 'subsidiarity' is evident in the practice of grass-roots politics, the avoidance of hierarchies, and the central role of town assemblies. The very low resource costs sustainability requires are achievable because of the proximity, diversity of functions and integration, the familiarity enabling 
informal communication and spontaneous action, and the elimination of many processes (e.g., transport, waste dumping, fertilizer production, packaging).

In the 1930s the Spanish Anarchists in the Barcelona region showed what could be done by ordinary workers and citizens. An impressive current example is the Catalan Integral Cooperative movement (Dafermos 2017; TSW 2015a). Thousands work in hundreds of different cooperatives providing hundreds of thousands of dollars worth of food, goods and services, including unemployment and other welfare services. They operate more than twenty food 'pantries' largely via voluntary labor, handling more than a thousand products. Their goal is to build an alternative society focused on meeting needs, with no involvement of the state or market principles. Many eco-villages operate according to Anarchist principles, achieving high levels of sustainability (again see Lockyer 2017 and Grinde et al. 2018).

In addition it will be evident that the discussion of transition strategy also follows Anarchist principles, especially in the notion of 'prefiguring' the new here and now within the old, not depending on the centre let alone a vanguard party, and recognizing the importance of ideas and values.

\section{The advent of $G F C 2$}

Unfortunately the foregoing transition sequence is likely to be greatly disrupted and possibly thwarted a global financial crisis of much greater magnitude than the 2008 event. It is widely recognized that the much higher levels of debt are likely to bring on at least a serious recession, and probably worse in the next few years. The global economy is heavily dependent on petroleum supply, which is been kept up by 'fracking', but this has only been made possible by enormous debt; none of the major companies in the arena has ever made a profit. Several analysts have pointed out that the price levels necessary to make the new sources of petroleum profitable now seem to be above those necessary to enable economies to function normally. In addition, Ahmed (2017) has argued persuasively that the rapidly worsening population, food, water and ecological conditions affecting Middle Eastern petroleum suppliers are increasing their chances of becoming failed states. Meanwhile the proportion of their petroleum production they must use internally is increasing, adding to the possibility that their capacity to export will dry up within a decade. These and other deteriorating resource and ecological conditions (especially falling Energy Return on Energy Invested rates) are likely to trigger serious global economic disruption long before localist initiatives have been well enough established.

Yet it is very unlikely that the kind of transition envisaged could begin unless there is major breakdown in the existing consumer-capitalist system. As long as it keeps the supermarket shelves stocked, discontent is likely to be muted, and focused on demands for more jobs and higher incomes rather than system replacement. The Goldilocks outcome would seem to be an economic depression that falls short of catastrophic breakdown, but is serious enough to convince large numbers that the system is not going to provide for them.

\section{The challenge to the Left}

This analysis has especially important implications for those who are radically critical of consumercapitalist society. Firstly it is evident that the revolution required to solve the problem is far bigger than that which Marx envisaged. Merely getting rid of capitalism will not suffice. Secondly, the most promising frontier now for such critics is the challenge to current society being set by unsustainable resource and ecological impacts. Latouche said the limits to growth are giving critical theory its last chance (2012: 75). Yet the foregoing argument has been that this opportunity has hardly been recognized, let alone taken up. Bookchin saw this some time ago. "The New Left, like the old left, has never grasped the revolutionary potential of the ecological issues, nor has it used ecology as a basis for understanding the problems of communist reconstruction and utopia" (1973: 242). Significant and increasing numbers of ordinary people are seriously concerned about these issues and are thinking more or less in the general direction of replacing consumer-capitalism with localism and simpler ways. These themes are likely to be the most effective foundations for critical social theory and practice now. 
But unfortunately the Left has a deeply entrenched reluctance to embrace these ideas. The traditional assumption has been that when power has been taken from the capitalist class, the contradictions preventing full application of the productive forces will be removed and technical advance will lift all to material wealth. Socialism is distinctly not conceived today in terms of frugality or localism. Indeed some socialists embrace 'ecomodernist' ideas, notably Phillips (2014) and Sharzer (2012), who explicitly spurn the suggestion that local or simpler ways are necessary or desirable.

David Harvey represents the many Marxists who reject localism both as a goal and as a revolutionary strategy in favor of the typical socialist focus on action at the state level (Harvey 2017). For a critique, see Springer (2017). The Marxist position fails to address current circumstances, where the goal must be to contradict individualistic competitive affluence and must focus on citizen involvement in local economies. Major change at the central or state level cannot be achieved before a profound cultural revolution has been achieved, and this is most likely to occur via developments at the local level.

\section{Delusion and denial: the inability to respond}

There are difficult and puzzling issues for social theorists that will not be taken up in this article. They are the psychological and institutional reasons for the failure to deal adequately with the limits to growth predicament, or with its major sub-problems such as the looming petroleum supply, debt, and climate change crises. The core phenomenon to be explained here would seem to be failure to even recognize the existence and/or seriousness of the problems, rather than lack of appropriate remedial action.

The essential causal factor is surely that if the limits to growth analysis is accepted then perhaps the most deeply entrenched post-Enlightenment assumption has to be jettisoned, i.e., the taken-for-granted conviction that progress and the good life are defined by capacity to produce and consume more and more material wealth. The suggestion that the supreme social goal should be materially simple lifestyles and systems, with no prospect of rising to greater affluence over time, would seem to be about as distasteful and unthinkable to workers and the lumpenproletariat as to the super-affluent $1 \%$.

\section{Conclusions: a reorientation of social theory}

The argument is that the advent of the limits to growth issue should be seen as requiring a major shift in the focal concerns of social theorists, especially those interested in critical perspectives on contemporary society and in sustainability and utopian themes. To begin with, a limits perspective involves a commitment to an inescapable logic that leads to quite specific conclusions regarding desirable social forms and how they might be achieved. If the limits are as severe as has been argued, then the goal must be transition from consumer-capitalist society to a general form that involves far lower resource use, and this has to mean mostly small-scale local economies that are self-governing, basically cooperative and committed to materially frugal lifestyles. If this is so, then the transition is essentially a cultural problem, and it is difficult to imagine how these ways could be established other than through a slow grass-roots process whereby ordinary people increasingly coerced by scarcity and economic deterioration take on the restructuring of their own suburbs, towns and regions (Alexander and Gleeson 2019). A major implication drawn above is that centralized agencies, especially the state, cannot drive these changes through.

Again, the argument has not been that these conclusions regarding goals or processes are likely to be realized. It has been primarily a drawing of logical implications from an analysis of our situation. However a merit of the general vision arrived at here is that by pointing to solutions that are technically simple and resource-cheap, it enables a degree of optimism regarding the possibility of avoiding chaotic global breakdown in the coming decades.

\section{References}

Ahmed, N.M. 2017. Failing states, collapsing systems. Dordrecht: Springer.

Albert, M. 2003. Parecon: life after capitalism. London: Verso. 
Alexander, S. 2012. Living better on less? Toward an economics of sufficiency. Simplicity Institute Report $12 \mathrm{c}$.

Alexander S. and B. Gleeson. 2019. Degrowth in the suburbs: a radical urban imaginary. London: Palgrave MacMillan.

Appfel-Marglin, F.A. 1998. The spirit of regeneration: Andean culture confronting western notions of development. London: Zed.

Avineri, S. 1968. The social and political thought of Karl Marx. Cambridge: Cambridge University Press.

Bideleaux, R. 1985. Communism and development. London: Methuen.

Bookchin, M. 1973. Post scarcity anarchism. Berkeley: Ramparts Press.

Bookchin, M. 1977. The Spanish anarchists: the heroic years. New York: Free Life Editions.

Bookchin, M. 1980. Towards an ecological society. Montréal: Black Rose.

Buber, M. 1958. Paths in Utopia. Boston: Beacon Press.

Dafermos, G. 2017. The Catalan Integral Cooperative: an organizational study of a post-capitalist cooperative. Commons Transition website.

Carrington, D. 2018. Humanity has wiped out $60 \%$ of animal populations since 1970, report finds. The Guardian $10^{\text {th }}$ Oct.

Duncan, R.C. 2013. The Olduvai theory: heading into the Gorge. The Social Contract 23(2): 44-49.

Eckersley, R. 2004. Well and good: morality, meaning and happiness. Melbourne: Text Publishing.

Fotopoulos, T. 1997. Towards an Inclusive Democracy. London: Cassell.

Grinde, B., R. Bang Nes, I.F. MacDonald and D.S. Wilson. 2018. The quality of life in intentional communities. Social Indictors Research 137(2): 625-640.

Harvey, D. 2017. 'Listen, Anarchist!' A personal response to Simon Springer's 'Why a radical geography must be anarchist'. Dialogues in Human Geography 7(3): 233-250. $\underline{\mathrm{draft}}$

Hatherley, O. 2012. Rebel cities: from right to the city to the urban revolution by David Harvey - review. The Guardian. 12 April.

Henfrey, T. and L. Ford. 2018. Permacultures of transformation: steps to a cultural ecology of environmental action. Journal of Political Ecology 25: 104-119.

Illich, I. 1973. Tools for conviviality. London: Marion Boyars.

Kitching, G.N. 1989. Development and underdevelopment in historical perspective: populism, nationalism, and industrialization. London: Routledge.

Kolbert. E. 2014. The sixth extinction. New York: Henry Holt and Co.

Korowicz, D. 2012. Trade: financial system supply-chain cross-contagion: a study in global systemic collapse. Tipperary: Metis Risk Consulting and Feasta.

Korten, D.C. 1999. The post-corporate world. West Hartford: Kumarian Press.

Kovel, J. 2007. The enemy of nature. London: Zed.

Kropotkin, P. 1898. Fields, factories and workshops: or industry combined with agriculture and brain work with manual work. New York: G.P. Putnam's Sons.

Kunstler, J. 2005. The long emergency: surviving the converging catastrophes of the twenty-first century. New York: Grove/Atlantic.

Latouche, S. 2012. Can the Left escape economism? Capitalism, Nature, Socialism 23(1): 74 -78.

LeBillon, P. and R. Duffy. 2018. Conflict ecologies: connecting political ecology and peace and conflict studies. Journal of Political Ecology 25: 239-260.

Lockyer, J. 2017. Community, commons, and de-growth at Dancing Rabbit Ecovillage. Journal of Political Ecology 24: 519-542.

Lowy, M. 2015. Eco-socialism: a radical alternative to capitalist catastrophe. London: Haymarket Books. 
Marshal, P. 1992. Demanding the impossible: the history of anarchism. London: Harper Collins.

Marx, K. 1871. The Civil War in France. Multiple editions.

Marx, K. 1887. Capital: a critique of political economy, Vol. 1. Moscow: Progress Publishers.

Mason, C. 2003. The 2030 spike: countdown to catastrophe. London: Earthscan.

Meinshausen, M, N. Meinshausen, W. Hare, S.C.B. Raper, K. Frieler, R. Knuitti, D.J. Frame and M.R. Allen. 2009. Greenhouse gas emission targets for limiting global warming to 2 degrees C. Nature 458(April 30): 1158-1162.

Mies, M. and V. Shiva 1993. Ecofeminism. London: Zed.

Morgan, T. 2013. Perfect storm: energy, finance and the end of growth strategy. London: Tullet Prebon.

Pepper, D. 1996. Modern environmentalism. London: Routledge and Kegan Paul.

Phillips, L. 2014. Austerity ecology and the collapse-porn addicts: a defence of growth, progress, industry and stuff. Winchester: Zero Books.

Quinn, D. 1999. Beyond civilization. New York: Three Rivers Press.

Rai, M. 1995. Chomsky's politics. London: Verso.

Relocalise. 2009. Relocalise website. http://www.postcarbon.org/relocalize

Rude, C. 1998. Postmodern Marxism: a critique. Monthly Review 50(6): 52-57.

Sarkar, S. 1999. Eco-socialism or eco-capitalism? A critical analysis of humanity's fundamental choices. London: Zed.

Shanin, T. (ed.). 1983. Late Marx and the Russian road. New York: Monthly Review Press.

Sharzer, G. 2012. No local: why small-scale alternatives won't change the world. Winchester: Zero Books. Simplicity Institute. 2018. Simplicity Institute website. http://simplicityinstitute.org

Speth, G. 2001. A bridge at the end of the world. New Haven: Yale University Press.

Springer, S. 2017. The limits to Marx: David Harvey and the condition of postfraternity. Dialogues in Human Geography 7(3): 280-294.

Trainer, T. 1995. The Conserver Society: alternatives for sustainability. London: Zed.

Trainer, T. 2012. De-growth: do you realise what it means? Futures 44: 590-599.

Trainer, T., A. Malik and M. Lenzen. 2019. Comparing the monetary, resource and ecological costs of industrial and Simpler Way local production: consider egg supply. (In press.)

TSW. 2010. Third world development. The Simpler Way website, authored by Ted Trainer. http://hesimplerway.info/ThirdWorldDev.long.htm

TSW. 2012. The spiritual significance of The Simpler Way. The Simpler Way website, authored by Ted Trainer. http://thesimplerway.info/Spiritual.htm

TSW. 2013. The Chikukwa Project: local permaculture-based alternative development in Zimbabwe. The Simpler Way website, authored by Ted Trainer. http://thesimplerway.info/CHIKUKWA.htm

TSW. 2014. The case against the market. The Simpler Way website, authored by Ted Trainer. http://thesimplerway.info/MARKET.htm

TSW. 2015a. The Catalan Integral Cooperatives...The Simpler Way revolution is well underway! The Simpler Way website, authored by Trainer. http://thesimplerway.info/Alts.CatalanICooperatives.htm

TSW. 2015b. The case for simplicity. The Simpler Way website, authored by Ted Trainer. http://thesimplerway.info/SIMPLICITY.htm

TSW. 2016a. But can't technical advance solve the problems? The Simpler Way website, authored by Ted Trainer. http://thesimplerway.info/TECHFIX.htm

TSW. 2016b. Decoupling: the issue, and collected evidence. The Simpler Way website, authored by Ted Trainer. http://thesimplerway.info/DECOUPLING.htm 
TSW. 2016c. Remaking settlements: the potential cost reductions enabled by The Simpler Way. The Simpler Way website, authored by Ted Trainer. http://thesimplerway.info/RemakingSettlements.htm

TSW. 2017. The limits to growth. The Simpler Way website. http://thesimplerway.info/LIMITS.htm

TSW. 2018. The Simpler Way alternative society. The Simpler Way website, authored by Ted Trainer. http://thesimplerway.info/THEALTERNTIVELong.htm

U.N. 2015. World population projected to reach 9.7 billion by 2050. 29 July. New York.

Vidal, J. 2010. Soil erosion threatens to leave earth hungry. The Guardian. Dec. $15^{\text {th }}$.

Weidmann, T.O., H. Schandl and D. Moran. 2015. The footprint of using metals: new metrics of consumption and productivity. Environmental Economics and Policy Studies 17(3): 369-388.

World Wildlife Fund. 2014. The Living Planet report 2014. World Wildlife Fund and London Zoological Society. 